Stoa

Vol. 2, No. 3, 2011, pp. 27-48

ISSN en trámite.

\title{
¿A QUIÉN PERTENECE LA CULTURA? REFLEXIONES SOBRE UN BIEN COMÚN EN LA ECONOMÍA DEL CONOCIMIENTO
}

\author{
AHTZIRI MOLINA ROLDÁN \\ Programa de Investigación en Artes \\ Universidad Veracruzana \\ ahtziri@gmail.com
}

RESUMEN: A lo largo de la historia, se han dado múltiples definiciones de lo que es cultura, las cuales están de acuerdo con las corrientes teóricas, el momento histórico en que aparecen y su lugar de origen. Por ello se han desarrollado tantas posturas teóricas ( hablar de) como marcos para la acción (hablar para) desde distintos podios de observación. Considero que en el contexto actual de globalización, donde el mercado es el principal móvil, es preciso inquirir sobre el valor de cambio que esta característica exclusiva de la humanidad ha adquirido. Por lo tanto este trabajo trata de responder a la pregunta retórica: ¿A quién o quiénes pertenece la cultura en la "era del conocimiento"? La exploración de las posibles respuestas se despliega siguiendo el desarrollo histórico de las distintas nociones de cultura y cómo las reflexiones y acciones sobre este término han sido relevantes en distintos aspectos de la vida en cada contexto. PALABRAS CLAVE: Teoría de la cultura, sociedad del conocimiento; cultura y mercado; multiculturalismo.

SUMMARY:Throughout history, there have been several different definitions of what culture is, which use to agree with the theoretical and historical moment in which they appear and their place of origin. So, There have been as much theoretical positions (talking about) as frameworks for action (talking to) from different podiums of observation. I believe that in the current context of globalization where the market is the mean motive, we should inquire about the exchange value that this unique feature of mankind has acquired. Therefore this paper tries to answer the rhetorical question: Who belongs culture in the "knowledge age $e^{c}$ The exploration of the possible answers are displayed following the historical development of different notions of culture and exploring how the ideas and actions on this term have been relevant in various aspects of life in each context. 
KEY WORDS: Theory of culture; society of knowledge; culture and market; multiculturalism.

\section{Introducción}

El día de hoy, la UNESCO, organismo internacional encargado de promover y monitorear las acciones y las políticas culturales, define a la cultura como:

El conjunto de los rasgos distintivos, espirituales y materiales, intelectuales y afectivos que caracterizan a una sociedad o un grupo social. Ella engloba, además de las artes y las letras, los modos de vida, los derechos fundamentales al ser humano, los sistemas de valores, las tradiciones y las creencias. Y que la cultura da al hombre la capacidad de reflexionar sobre sí mismo. Es ella la que hace de nosotros seres específicamente humanos, racionales, críticos y éticamente comprometidos. A través de ella discernimos los valores y efectuamos opciones. A través de ella el hombre se expresa, toma conciencia de sí mismo, se reconoce como un proyecto inacabado, pone en cuestión sus propias realizaciones, busca incansablemente nuevas significaciones, y crea obras que lo trascienden. (UNESCO 1982, p. 1)

Si bien, esta definición elaborada en 1982 es importante porque fue hecha con fines prácticos, para la elaboración de políticas culturales, y es la que se aplica de forma cotidiana para pensar la cultura desde los gobiernos y otras fuentes promotoras de acciones culturales. Esta definición aún es funcional, está siendo ampliamente cuestionada por las prácticas y formas culturales actualmente existentes. La globalización, producto y generadora del libre mercado, cuestiona las definiciones básicas sobre lo que es la cultura, cómo se define, cómo se incorpora en la sociedad y cómo se vive. En este artículo, con la finalidad de hacer un balance sobre el estado actual de la cultura, revisaremos someramente las nociones básicas propuestas por el discurso común, la tradición filosófica literaria, la tradición antropológica, la marxista, la concepción simbólica de la cultura, la identidad y memoria colectiva, la dinámica cultural y los estudios de multiculturalidad. A la luz de estos cuerpos teóricos se reflexionará sobre los usos dados a este término en distintos contextos y momentos históricos, y la pertinencia y presencia que lo sostienen el día de hoy. Las posturas predominantes han desarrollado tanto enfoques teóricos (hablar de) como marcos para la acción ( hablar para) desde sus podios de observación particulares. Estos serán los materiales a partir de los cuales reflexionaremos 
sobre el hecho que nos preocupa en este artículo: en tiempos de globalización y mercado mundial ¿A quién pertenece la cultura? Ylas preguntas que derivan de este hecho: ¿Quiénes la producen, la manipulan, quiénes se la apropian y cómo la generan? Para la realización de este trabajo se retoma el recorrido teórico y la síntesis elaborada por Giménez (2005 ) y se complementa con los preceptos de Touraine y Monges sobre multiculturalidad e interculturalidad.

\section{Revisión histórica}

El término cultura admite dos grandes familias de acepciones: las que refieren a la acción o proceso de cultivar, y las que refieren al estado de lo que ha sido cultivado, que pueden ser, según los casos, estados subjetivos o estados objetivos. (Giménez 2005, p. 33) Para comenzar el sentido común ha acuñado términos que derivan del origen de la palabra y desde tiempos inmemoriales han funcionado como referente básico. La primera acepción está relacionada con la acción de cultivar, sea la tierra o las acciones humanas hechas en sociedad. Durante el siglo XV se aplica únicamente al cultivo de la tierra (Charpentraux 1962) mientras que en el siglo XVIII los filósofos alemanes (Imbert 1979) confieren a la cultura un sentido totalizante, como un ideal de vida colectiva que abarca la totalidad de las acciones humanas (Herder) o como un conjunto de rasgos históricos-sociales que caracteriza a una nación y garantiza a identidad colectiva de los pueblos (Fitche).

Es en este siglo, el XVIII, cuando la cultura también se constituye como un campo especializado y autónomo, y lo que le da su sello es que se convierte en un campo independiente de toda función práctica y social. lo cual permitió que la cultura se transformara en una noción centrada en sí misma. Como consecuencia se comienzan a identificar acciones y objetos como "culturales", tales como el patrimonio material que se ve como la esencia de la cultura. La consecuencia de identificar la noción de cultura con las bellas artes fue pensarla como obra y propiedad de unos cuantos privilegiados: quienes pueden realizar obra o apreciarla desde sus capitales culturales y socio-económicos, de modo que desde esta óptica no todos los humanos tendrían la posibilidad de convertirse en "personas cultas". Esto genera divisiones socioculturales entre los segmentos de los grupos sociales, lo que más adelante Bourdieu (2002) identificará como la distinción y marcará las pautas de las ideologías que darán 
identidad y sentido a las comunidades y los segmentos que las integran. De Varine (1976, pp. 33 y ss.) considera que la cultura ya autonomizada y definida ha ido pasando por diferentes fases La primera fase se despliega a todo lo largo del siglo XIX puede llamarse fase de codificación de la cultura. Ésta consiste en la elaboración progresiva de claves y de un sistema de referencias que permitieron fijar y jerarquizar los significados y valores culturales, tomando inicialmente por modelo la "herencia europea" con su sistema de valores heredados, a su vez, de la antigüedad clásica y de la tradición cristiana. El resultado de este proceso de codificación fue que se generaron círculos concéntricos, rígidamente jerarquizados: el círculo interior de la alta cultura 'legitima' que tiene como vehículo las bellas artes, el círculo intermedio de la cultura tolerada y el círculo exterior de la intolerancia y la exclusión. De estas acepciones deriva el hecho de que aún el día de hoy se sobreponga a las bellas artes sobre otras expresiones culturales y sobre todo, se interprete que las artes no son susceptibles de ser disfrutadas y comprendidas por todos los seres humanos, sino únicamente por los grupos que cuentan con el capital cultural y social que les permite gozarlo.

Con el comienzo del siglo XX, la cultura es institucionalizada en el sentido político-administrativo (Warniern 2004). Este proceso puede interpretarse como un esfuerzo secular del Estado por lograr el control y la gestión de la cultura, bajo una lógica homogeneizante El Estado se convierte en el regulador de los bienes culturales que son generados en gran medida por las comunidades artísticas, las elites, que para entonces han diferenciado claramente los gustos y las identificaciones culturales-identitarias derivándolas de referentes inmediatos diferenciados por contexto, grupo social e intereses personales. En esta etapa comienzan las políticas culturales del Estado que han de regir la actividad cultural a lo largo del siglo XX. Hay una tercera fase, la cual comenzó en la década de los años ochenta del siglo pasado, y es en la que vivimos en la actualidad: la mercantilización de la cultura. Esta fase implica la subordinación masiva de los bienes culturales a la lógica del valor de cambio y al libre mercado, junto con otros aspectos de la vida social, que durante décadas fueron regulados y protegidos por el Estado, como la salud, la educación e incluso el crecimiento de las empresas. Esta concepción de la cultura de la mano del mercado, le regresa un sentido práctico, en cuanto las produccio- 
nes culturales se expanden masivamente y por lo tanto generan patrones de consumo y hábitos culturales similares en distintas partes del mundo. Debido a que la cultura ha pasado a ser un activo del capital, su sentido se ha modificado e incluso desaparecido en función del mercado, perdiendo su gratuidad, y su función de promotora de la identidad y el tejido social. Por lo tanto en la sociedad actual, además de los valores tradicionales que se le han dado a la cultura-como bien simbólico, social y político- ahora se agrega el bien mercantil que este aspecto de la vida social tiene. Por lo tanto, la cultura se sitúa el día de hoy en una posición distinta a la planteada por los filósofos del siglo XVIII, de ahí que se encuentre la necesidad de revisar los postulados teóricos emitidos a lo largo del tiempo, para identificar como llegamos a las formas y prácticas contemporáneas.

\section{La Cultura A Los Ojos De La Antropología}

La antropología, disciplina dedicada al estudio de la humanidad de forma integral, fue la primera disciplina social en estudiar la cultura de forma completa. Esta disciplina tiene sus primeros fundamentos en tres naciones, Inglaterra, Estados Unidos y Francia, perola mayoría de los estudios que se hicieron en sus orígenes se referían a pueblos originarios de lugares ubicados fuera de Europa y América del Norte, en regiones menos industrializadas o en vías de desarrollo, donde los capitales de las naciones de las que provenían los primeros antropólogos tenían presencia imperial. Estos estudiosos fueron los primeros en romper con la concepción euro céntrica elitista y restrictiva de la cultura, sustituyéndola por "una concepción total" basada en la relatividad y universalidad: para los antropólogos, todos los pueblos, sin excepción, son portadores de cultura. La tradición antropológica que se desarrolló a finales del siglo XIX, tuvo en Edward B. Tylor a su primer representante y, este autor inglés definió a la cultura como un bien universal de todas las comunidades. Para Tylor -identificado con el evolucionismo cultural-, la cultura es un proceso y consecuencia de la evolución lineal de todos los pueblos que comienza con la cultura primitiva y eventualmente llega a la civilización. Para 1871, Tylor introduce en su libro: Primitive Culture la "concepción total" de la cultura, que define como: "el conjunto complejo que incluye el conocimiento, las creencias, el arte, la moral, el derecho, la costumbre y cualquier otra capacidad o 
hábito adquirido por el hombre en cuanto miembro de la sociedad". Comprende, por lo tanto, las actividades expresivas de los hábitos sociales y los productos intelectuales o materiales de estas actividades. Sin embargo, el día de hoy es cuestionable esta visión positivista y lineal de la construcción cultural. $\mathrm{Si}$ bien se entiende que las culturas son dinámicas y tienden a cambiar, no existe parámetros definitivo sobre cuáles son las características y manifestaciones $\mathrm{Ne}$ cesarios en la evolución de los pueblos para alcanzar el estado de civilización. Posteriormente Franz Boas, Robert Lowie y Alfred Kroeber, padres de la antropología norteamericana, clamaron que existe una pluralidad irreductible como resultado del contacto entre las diversas culturas: Y señalaron también que, el intercambio dinámico de cada cultura con otras, no siempre se puede leer como un bien común, pues existen algunas culturas que predominan , Sobre esto podríamos indicar que este proceso generalmente va acompañado de dominación política, económica o militar, y por lo tanto, como práctica cotidiana la posibilidad de elegir si se quiere o no la aculturación es restringida o casi nula. A partir de los años treinta se generaliza en los Estados Unidos una nueva definición, obra de la llamada escuela culturalista, cuyos representantes principales fueron los discípulos de Boas. En ella se entiende por cultura: "todos los esquemas de vida producidos históricamente explícitos o implícitos, racionales, irracionales o no racionales, que existen en un determinado momento como guías potenciales del comportamiento humano". (Rossi, P. en Giménez 2005, p. 44) El proceso de aprendizaje de la cultura dentro del propio grupo suele llamarse en esta teoría "inculturación". Pero este aprendizaje puede producirse también por vía exógena, en el marco de los fenómenos de difusión o de contacto intercultural, proceso llamado "aculturación" (Ibídem, p. 45). Según los culturalistas, la actitud de los individuos respecto de su propia cultura está lejos de ser puramente pasiva. Por otra parte, Claude Levi-Strauss en Francia es el primero en postular que la cultura es un sistema de reglas y que pertenece al mundo de lo simbólico, a pesar de las múltiples materializaciones que presenta. Según Levi-Strauss la ausencia o la presencia de reglas es lo que distingue a la cultura de la naturaleza. El señalamiento de que la cultura pertenece al ámbito simbólico será un paso muy importante para la identificación y deslinde de los objetos que le pertenecen, y su inclusión en la vida social, o cómo se constituye la naturaleza como parte de la vida social, des- 
de la lógica de ordenamiento simbólico que plantea este autor. Para Bronislaw Malinowski, refundador de la antropología social británica, la organización social "no puede comprenderse sino como parte de la cultura". Entonces, "es la misma cultura la que transforma a los individuos en grupos organizados y la que asegura a estos últimos "una continuidad casi indefinida (Ibídem, p. 49). Este autor pertenece a una tradición fuertemente influenciada por la escuela durkheimiana (Marcel Mauss, Lucien Levi-Bruhl), y quizá por ello, la antropología social británica afirma la necesidad de estudiar cualquier forma de organización social con los instrumentos propios de análisis sociológico. Estos son algunos de los principales referentes antropológicos de la cultura y es a partir de ellos que el concepto de cultura asume su carácter universalista, sin embargo el enfoque antropológico también es más abstracto y abre la posibilidad de pensar a los pueblos como entes activos y transformadores de la cultura propia y de otras y conlleva la noción de poder de unos pueblos sobre otros. La lectura que esto adquiere desde la propia disciplina, y otras afines, pasa por la preservación de las expresiones auténticas de los pueblos y su 'defensa' ante otras interacciones o intervenciones como la posibilidad de que unos grupos prevalezcan sobre otros.

\section{La Ideología como motor de la Lucha de Clases}

La tercera corriente teórica que tiene una amplia presencia en el tema es el marxismo. Esta teoría social, que tiene sus bases en el análisis económico del desarrollo industrial y el consecuente capitalismo de la segunda mitad del siglo XIX en Europa, aportó elementos importantes para el análisis cultural. En la actualidad algunos de estos postulados, como el concepto de capital y el de lucha de clases resultan muy relevantes para comprender las acciones culturales que suceden en la globalización. Es importante señalar que el marxismo no maneja el término de cultura per se, sino lo homologa con la ideología, siéndola cual es una de las nociones más importantes dentro del pensamiento marxista. Esta teoría nos pone muy cerca del uso masificado de la cultura, pues se acerca a ella desde la problemática de la producción cultural con relación a la lucha de clases y desde una perspectiva políticamente valorativa. Esto es particularmente cierto desde los postulados del propio Marx y de Lenin. Los autores de esta corriente tienden a oponer los términos de cultura dominan- 
te, burguesa, contra las culturas dominadas del campesinado tradicional y ven en la cultura obrera una alternativa de liberación para los diversos grupos sociales y para el mundo. Por otra parte, esta concepción considera a la cultura nacional como la cultura de los terratenientes, del clero y de la burguesía, y a la cultura obrera como cultura internacional. Según el marxismo la cultura se constituye a partir de factores extra culturales: condiciones materiales de existencia-dominación-subordinación como efecto de la lucha de clases. Además, desde la perspectiva de Lenin, la cultura es indisociable de su contexto histórico. Por su parte Gramsci, a principios del siglo XX, desarrolla en Italia la noción de cultura como concepción del mundo. Desde su perspectiva, la cultura no sería más que una visión del mundo interiorizada colectivamente como "religión" o "fe", es decir, como una norma práctica o "premisa teórica implícita" de toda actividad social. La cultura así entendida posee una eficacia integradora y unificante, de modo que determina la identidad colectiva de los actores histórico-sociales. Para Gramsci las ideologías "organizan" a las masas humanas, forman el terreno dentro del cual se mueven los hombres, adquieren conciencia de su posición y luchan. Este autor aborda los problemas de la ideología y de la cultura en función de una preocupación estratégica y política motivada en gran parte por la derrota histórica del proletariado europeo en los años veintes. De aquí la estrecha vinculación de su concepto de cultura con el de hegemonía, que representa groso modo una modalidad de poder -capacidad de educación y dirección- basada en el consenso cultural. La cultura, al igual que la ideología, se convierte en instrumento privilegiado de la hegemonía por medio de la cual una clase social logra el reconocimiento de su concepción del mundo y, en consecuencia, de su supremacía sobre las demás clases sociales (Giménez 2005, p. 60). Es así como la hegemonía va unida al peso de la cultura como instrumento para transmitir el reconocimiento de su concepción del mundo. La posición de clase subalterna y/o dominante determina, según Gramsci, una gradación de niveles jerarquizados en el ámbito de la cultura, que van desde las "filosofías" hegemónicas y la religión a las menos elaboradas y refinadas, como el sentido común y el folklore, que grosso modo suele denominarse "cultura popular". Gramsci matiza significativamente su posición frente a las culturas subalternas, reconociendo en ellas elementos o aspectos progresistas capaces de servir como punto de partida para una 
pedagogía a la vez política y cultural que encamine a los estratos populares hacia "una forma superior de cultura y de concepción del mundo". (Gramsci, 1975, p. 17) Como es posible observar, aunque existen distintos acercamientos a la cultura desde el marxismo, el elemento fundamental de la lucha de clases aparece en todos los trabajos propios de esta corriente. En este sentido, la pregunta guía de este texto se contesta con facilidad: la cultura está asociada con la clase y, dada la lucha de clases, la hegemonía sigue perteneciendo a aquellos que detentan el poder económico y la ideología que los sostiene. Sin embargo, el análisis no es tan sencillo en las condiciones actuales, pues una de las fuerzas más importantes del mercado actual es el proceso de internalización que promueven esos postulados hegemónicos a nivel mundial mediante la introducción de "productos" atractivos a grupos "simbólicos" en vías de homologación en todo el globo, lo que conduce a que la uniformidad de la simbología aportada por la mercadotecnia genere la ilusión de la pertenencia a este mercado mundial. Lo anterior si no elimina las diferencias de clase, sí las hace borrosas y desdibuja el sentido de clase y los actores identitarios o ideológicos, en contraste con las evidencias de la lucha de clases que se hacían sentir con mayor énfasis en el pasado, generando la ilusión de que las clases dejan de ser relevantes y por lo tanto la lucha desapareciera, aunque esto, en realidad, no sucede.

\section{Semiótica y Cultura: La Concepción Simbólica}

La cultura ha sido abordada como código o sistema de reglas por la antropología estructural; como ideología y concepción del mundo por la tradición marxista; como "sistema cognitivo de valores y evaluativo" por algunos exponentes de la demología italiana de inspiración gramsciana; como "modelo" o "pauta de comportamiento" por los culturalistas; como "esquemas interiorizados de percepción, de valoración y de acción” por la sociología de Pierre Bourdieu; y, en fin, como "sistema modelante secundario", susceptible de tipologización, por la semiótica soviética de la cultura (Giménez 2005, p. 74). Todos estos enfoques tienen en común el reconocimiento de la naturaleza semiótica de la cultura, y por eso no son excluyentes sino complementarios entre sí. En el marco de este artículo preferimos abordar la cultura, con Eunice Durham, desde una perspectiva dinámica, como un proceso que interrela- 
ciona los diferentes aspectos arriba señalados, que en realidad corresponden a diferentes momentos analíticamente separables de un mismo proceso de significación. Clifford Geertz (1992) y John B. Thompson (1990), fundadores de la antropología simbólica, desarrollaron en la segunda mitad del siglo XX la "concepción simbólica" o "semiótica" de la cultura. La cultura desde este enfoque se concibe como el conjunto de hechos simbólicos presentes en una sociedad; como la organización social del sentido: como pautas de significados "históricamente transmitidos y encarnados en formas simbólicas, en virtud de las cuales los individuos se comunican entre sí y comparten sus experiencias, concepciones y creencias". En Geertz, lo simbólico es el mundo de las representaciones sociales materializadas en formas sensibles llamadas "formas simbólicas" y que pueden ser expresiones, artefactos, acciones, acontecimientos y alguna cualidad o relación. Lo simbólico recubre el vasto conjunto de los procesos sociales de significación y comunicación. Geertz identifica tres grandes problemáticas: esta triple problemática de la significación-comunicación se convierte también, por definición, en la triple problemática de la cultura. 1) La problemática de los códigos sociales, 2) la problemática de la producción del sentido y 3) la problemática de la interpretación o del reconocimiento. (Giménez 2005, p. 70) En la primera fase, la cultura es vista como una dimensión constitutiva de todas las prácticas sociales, de toda la vida social: la cultura está en todas las acciones humana, los sistemas simbólicos son al mismo tiempo representaciones ("modelos de") y orientaciones para la acción ("modelos para”), según la expresión del propio autor (Geertz 1992, p. 91) Así tenemos que desde esta perspectiva la cultura es entendida como repertorio de hechos simbólicos, manifiesta una relativa autonomía y también una relativa coherencia: 1) porque responde, por definición, a la lógica de una estructura simbólica, entendida saussurianamente como "sistema de oposiciones y diferencias"; 2) porque el significado de un símbolo frecuentemente desborda el contexto particular donde aparece, y remite a otros contextos. Las prácticas culturales se concentran, por lo general, en torno a nudos institucionales poderosos, como el Estado, las iglesias, las corporaciones y los medios masivos de comunicación, actores culturales también dedicados a administrar y organizar sentidos. Estas grandes instituciones (o aparatos), generalmente centralizadas y económicamente poderosas, no buscan la uniformidad cultural sino 
sólo la administración y organización de las diferencias, mediante operaciones como la hegemonización, la jerarquización, la marginalización y la exclusión de determinadas manifestaciones culturales. (Giménez 2005, p. 73) La cultura exhibe como primera propiedad la transversalidad, es decir, se nos presenta como ubicua, como una sustancia inasible, resistente a ser confinada en un sector delimitado de la vida social. Existen varios modos de caracterizar la cultura, de pensarla en conjunto. Ante la imposibilidad de experimentar todos los elementos de una cultura, se han desarrollado varias categorías, Brummet (1994) habla de los "textos culturales" como una alternativa para experimentar los fragmentos. Dichos "textos" serían conjuntos limitados de signos o símbolos relacionados entre sí en virtud de que todos sus significados contribuyen a producir los mismos efectos o tienden a desempeñar las mismas funciones (Giménez 2005, p. 76). Sin embargo, han perdido fuerza en la actualidad, debido a que estos modos de generar significados están siendo reemplazados por el mercado y su auto-regulación. Otra manera de acercarse a la cultura sería abordarla sectorialmente. Cada uno de los sectores tiende a convertirse en un universo autónomo, controlado por especialistas y dedicado a la producción de un sistema de bienes culturales, lo cual Bourdieu identifica como los campos. También está el llamado "enfoque dinámico", de acuerdo con el cual todos y cada uno de los sectores culturales pueden dividirse, a su vez, en cinco procesos que frecuentemente se articulan entre sí de manera muy estrecha: 1) la creación de obras culturales; 2) la crítica, que desempeña, de hecho, un papel de legitimación; 3) la conversación de las obras bajo múltiples formas (bibliotecas, archivos, museos, etcétera; 4) la educación, la difusión de las obras culturales y las prácticas de animación; 5) el consumo sociocultural o los modos de vida (ibídem, p. 77). Por último, se puede abordar el universo de la cultura estratificándolo según la estructura de clases, basadas en el marxismo, bajo el supuesto de que la desigualdad social genera una desigual distribución del poder que, a su vez, condiciona diferentes configuraciones o desniveles ideológico-culturales. Así tenemos que los comportamientos culturales siguen correlacionándose muy fuertemente con las posiciones y las trayectorias sociales y, de modo particular, con el capital cultural. Se trata de la distinción ente formas interiorizadas y formas objetivadas de la cultura. En palabras de Bourdieu (1990), entre "formas simbólicas" y estructuras mentales interiorizadas, 
por un lado, y símbolos objetivados bajo formas de prácticas rituales y de objetos cotidianos, religiosos, artísticos, etcétera, por otro. Dicho de otro modo: la cultura es, antes que nada, habitus (Bourdieu 1980, p. 87) y cultura-identidad (Di Cristoforo 1993, pp. 53-57), es decir, cultura actuada y vivida desde el punto de vista de los actores y de sus prácticas.las formas simbólicas interiorizadas, para cuyo estudio disponemos de dos paradigmas principales: el paradigma del habitus de Bourdieu, y el de las "representaciones sociales" elaborado por la escuela europea de psicología social liderada por Serge Moscovici. Estos dos autores, activos en la segunda mitad del siglo XX, forjaron escuela y sus nociones se encuentran presentes en muchos trabajos contemporáneos. Para Moscovici la representación social puede definirse como "conjunto de informaciones, creencias, opiniones y actitudes a propósito de un objetivo determinado" y Jodelet complementa el concepto diciendo que constituyen, "una forma de conocimiento socialmente elaborado y compartido, que tiene una intencionalidad práctica y contribuye a la construcción de una realidad común a un conjunto social". (Jodelet 1989, p. 36) Por lo tanto, si no se conoce la representación aludida, no hay apropiación posible. Las representaciones sociales no son un simple reflejo de la realidad sino una organización significante de la misma que depende, a la vez, de circunstancias contingentes y de factores más generales como el contexto social e ideológico, el lugar de los actores sociales en la sociedad, la historia del individuo o del grupo y, en fin, los intereses en juego. Estas representaciones tienen por lo menos cuatro funciones nucleares: 1) Función cognitiva, 2) Función identificadora, 3) Función de orientación y 4) La función justificadora. Mientras que el habitus de Bourdieu permite detectar esquemas subjetivos de percepción, valoración y acción, que son su definición misma y de lo que nosotros hemos llamado cultura interiorizada. Con Michel Bassand (1981, p. 9) podemos afirmar que la cultura no sólo esta socialmente condicionada sino que constituye también un factor condicionante que influye profundamente sobre las dimensiones económica, política y demográfica de cada sociedad. La concepción simbólica de la cultura es muy vigente el día de hoy pues permite analizar las condiciones culturales presentadas por los diversos grupos sociales del planeta. Este conjunto de nociones ponderan los roles jugados por los diversos actores y momentos, desde condiciones abstractas, y permite el análisis de los hechos desde el conocimiento de los códigos 
utilizados por cada grupo social, lo cual permite un análisis más homogéneo de prácticas más específicas.

\section{La Dinámica Cultural}

Un elemento básico en la constitución de la cultura es el hecho de que ésta es dinámica. Si bien la cultura genera identidad y memoria colectiva, también se modifica de acuerdo a las necesidades del tiempo y la gente que la vive. Es por lo tanto, muy importante entender que los procesos dinámicos de la cultura son vitales para que en su modificación pueda seguir existiendo. Para Fossaert la identidad, constituye un hecho enteramente simbólico construido en y por el discurso social común, porque solo puede ser efecto de representaciones y creencias pues supone un "percibirse" y un "ser percibido" en virtud del reconocimiento de los otros, de una "mirada exterior". La identidad no es solamente "efecto" sino también "objeto" de representaciones. (Giménez 2005, p. 90) Las identidades sociales solo cobran sentido dentro de un contexto de luchas pasadas o presentes: se trata, según Bourdieu, de un caso especial de la lucha simbólica por las calificaciones sociales, ya sea a nivel de vida cotidiana -en el discurso social común- , o en el nivel colectivo y en forma organizada, como ocurre en los movimientos de reivindicación regional, étnica, de clase o de grupo. Pero en el contexto de las luchas simbólicas por la clasificación "legitima" del mundo social, las identidades dominantes tienden a exagerar la excelencia de sus propias cualidades y costumbres y a denigrar las ajenas. De lo dicho hasta aquí se infiere que la identidad social es de naturaleza esencialmente histórica y debe concebirse como producto del tiempo y de la historia. Las identidades colectivas remiten frecuentemente a los orígenes asociados a la idea de una tradición o de una memoria. Por su parte la memoria puede definirse brevemente como la ideación del pasado, en contraposición a la conciencia -ideación del presente- y a la imaginación prospectiva o utópica -ideación del futuro, del porvenir- . Sin embargo, la memoria no se limita a registrar, rememorar o reproducir mecánicamente el pasado, sino que realiza un verdadero trabajo sobre él, un trabajo de selección, de reconstrucción y, a veces, de transfiguración o idealización ("cualquier tiempo pasado fue mejor”) (ibídem, p. 97). La memoria no es sólo "representación” sino también "reconstrucción"; no es sólo "memoria constituida" sino también "memoria 
constituyente". En términos de Fossaert diríamos que la memoria colectiva es aquélla que se constituye en y por el discurso social común, en el seno de redes sobre todo primarias, pero también secundarias, de sociabilidad, que dan origen a la proliferación de grupos o de colectividades concretas fuertemente auto-identificadas y conscientes de su relativa estabilidad a través del tiempo (ibídem, p. 100). La memoria colectiva se encuentra materializada en las instituciones sociales, en el espacio-tiempo de la comunidad y, en estrecha relación con éste, en la gestualidad festiva y ritual. La memoria colectiva es objeto y motivo de una enconada lucha de clases en el plano simbólico y revela un aspecto particular de la lucha ideológica: aquél que se refiere a la apropiación del pasado. Emerge una contraposición entre memoria oficial y memoria popular, por su parte la memoria oficial es la memoria de la clase dominante que se organiza bajo la cobertura y gestión del Estado. Por otra parte, si concebimos la cultura en términos simbólicos o representaciones, el cambio cultural tendrá que manifestarse obviamente en forma de movimientos o deslazamientos de significados y de la constelación simbólica que los sustenta. Estos movimientos y desplazamientos representan las posibilidades del cambio si tomamos como referencia la figura del signo como asociación de un significante con un significado. Existe el registro de cómo cambian los códigos y registros culturales, de cómo se modifican los significados y formas de hacer y a partir de este registro puede elaborarse una tesis según la cual el efecto de la modernización sobre la cultura es doble: por una parte desintegra o disuelve las culturas tradicionales y las identidades en ellas fundadas y, por otra, produce nuevas formas de cultura/identidad. Estos y otros argumentos condujeron a una nueva revisión del paradigma de la modernización, sobre todo en lo concerniente a la dicotomía tradición/modernidad. Clifford Geertz plantea abiertamente la posibilidad de reconciliar ambos polos. En contraste con la visión unilineal y evolucionista del paradigma dominante, el cambio hacia la modernización también puede apoyarse en la reactivación de la identidad colectiva anclada en paradigmas tradicionales básicos. El factor explicativo de la dinámica socio cultural se encuentra, según la psicología, en que las representaciones sociales cambian cuando se modifican las circunstancias exteriores dentro de las cuales operan, es decir, cuando se vuelven disfuncionales respecto de las nuevas circunstancias. Para Bourdieu el cambio cultural sucede cuando la modificación 
del habitus se puede homologar aproximadamente con la de las representaciones sociales, las que define como: "sistema subjetivo, pero no individual, de estructuras interiorizadas que son esquemas de percepción, de concepción y de acción”. En efecto para Bourdieu los sistemas de disposiciones, que él llama habitus, cambian y se transforman cuando operan en condiciones objetivas nuevas y diferentes de las que le dieron origen, porque, según este autor, la práctica es producto no sólo del habitus sino de la relación dialéctica entre situación y un habitus, cuya conjunción constituye la coyuntura. Otro factor de cambio son las relaciones conflictivas entre el conjunto de lo que él llama campos ideológicos especializados y la cultura común no especializada que tiene por soporte inmediato, no las instituciones sino las redes de sociabilidad: el vasto conjunto de las prácticas banales y de las representaciones usuales que dan contenido a la cotidianidad y puede homologarse al "sentido común" de Gramsci. Así pues, podemos redimensionar la noción de red social en los años recientes a partir de la irrupción de las redes cibernéticas, que permiten el uso y modificación de la identidad, como resultado de la identificación y formación de cuerpos y grupos que se equiparan, trabajan y actúan juntos, aunque sus integrantes no se conozcan cara a cara.

Por lo tanto, el "mundo cultural existente" (Gramsci) es un mundo permanentemente sometido a una doble presión contradictoria: la de los campos ideológicos especializados y la ejercida por la "resistencia de las representaciones populares conservadas en la red de los grupos sociales concretos". (Moscovici, en ibídem, p. 126)

Llegamos ahora a la raíz última que condiciona y explica la conflictualidad de todos los campos: la estructura de clases. Puede abordarse del siguiente modo: existe una relación significativa entre posiciones en la trama de las relaciones sociales y la cultura entendida como configuración de significados sociales diversamente interiorizados y objetivados.

La misma hipótesis permite a Bourdieu concebir la cultura como "la distinción" simbólicamente manifestada y clasistamente connotada; como una constelación jerarquizada y compleja de "ethos de clase" que se manifiesta en forma de comportamientos, consumos, gustos, estilos de vida y símbolos de status diferenciados y diferenciantes, pero también en forma de productos y artefactos diversamente valorizados. Dentro de este esquema, la cultura de las clases 
dominantes se impone como la "cultura legítima". O dicho de otro modo: el poder tiene por base y fundamento la estructura objetiva de la desigualdad social. (Giménez 1983, p. 23) La cultura es una herramienta importante desde el poder, especialmente el del Estado, pues la legitimación de las culturas dominantes ha tenido en esta instancia un gran aliado a través del cual puede imponer sus códigos, convirtiéndolos en las formas culturales dominantes. Una cultura hegemónica, por lo tanto, es aquella que reorganiza la totalidad de las "relaciones de sentido" en una determinada dominación social, no tanto imponiendo a todos sus propios modelos o parámetros sino logrando su reconocimiento universal como los únicos válidos y legítimos. (Giménez 2005, p. 128) Los medios de comunicación masiva tienen la tendencia a la "progresiva integración en un único sistema de todas las realidades socioculturales existentes, sean estas de carácter macro y micro" El resultado es la "aculturación de masa" y no cabe duda que la tendencia inherente a la globalización es la estandarización de la cultura, debido a que puede entenderse también como una forma de desarrollo planetario que niega la importancia de las culturas particulares, por la sencilla razón de que considera todo particularismo como un obstáculo para las transacciones económicas internacionales. La respuesta a la pregunta planeada en este artículo, desde el punto de vista de la concepción simbólica de la cultura, puede inferirse de esta definición de Greimas y Courtés que concentra los elementos hasta aquí enunciados: "la cultura no es más que la sociedad misma considerada como significación" (Greimas y Courtès 1979, p. 356). Lo que puede parafrasearse de este modo: la cultura es la sociedad considerada como estructura de sentido, como signicidad o semiosis, como representación, símbolo, teatralización, metáfora o glosa de sí misma.

\section{Multiculturalismo}

Una visión sobre la cultura inmersa en el contexto de la globalización es la del multiculturalismo. Ésta parte del hecho inminente de la socialización de las diferentes culturas en la actualidad. El multiculturalismo se puede entender tanto como un hecho social, una ideología o un proyecto político, los cuales buscarían caracterizar la pluralidad y heterogeneidad de distintas tradiciones y códigos culturales en una misma sociedad. Es la identificación de que las 
sociedades modernas no son comunidades, no son unidades homogéneas que compartan una conciencia colectiva o un sistema de creencias único como base de la cohesión interna. La idea de globalización se utiliza para señalar una actitud mental de apertura ante la diversidad cultural, esto es una disposición para el diálogo intercultural. Y en ocasiones también se presenta como una reacción contra la homogenización cultural planetaria. (Velasco 2000, p. 150) Para Touraine (1997, p. 5) la sociedad se basa en un principio universalista que permite la comunicación entre los individuos social y culturalmente diferentes. Este principio debe de ser el respeto a la libertad de cada uno, donde la diferencia y la igualdad no son contradictorias sino que son inseparables una de otra: una sociedad sin diferencias reconocidas sería una dictadura. Touraine plantea tres concepciones básicas de multiculturalismo: multiculturalismo como encuentro de culturas, como búsqueda del parentesco entre las distintas experiencias culturales y finalmente como búsqueda de comunicación entre conjuntos culturales que estuvieron separados hace mucho tiempo y clasificados según una lógica de dominación. Esta última es la acepción que presenta más riesgo a la hora de incorporarla a la vida cotidiana. También es la más cercana a la lucha de clases, a las expresiones de resistencia a la dominación cultural de los grupos más fuertes que muestran la tendencia a promover nuevas formas de interacción desde las contrapartes del mercado, las cuales, sin mucho interés por el discurso, han modificado ampliamente las prácticas a través de la generación o resignificación de códigos que les son convenientes y representan una alternativa frente a la interacción y la prevalencia del mercado en la imposición de la producción cultural y las modificaciones que esto implica en los patrones de las vidas conjuntas que se pueden o no expresar como comunidad. Para Touraine el objetivo de una sociedad multicultural debe ser permitir que todos los individuos puedan trabajar juntos y que sus diferencias culturales sean reconocidas e incluidas. Este autor señala, además, que dada la desregulación del mercado y las sociedades que ha implicado el proceso de globalización, las sociedades se han roto y propone una firme intervención estatal para que las desigualdades y la precariedad no se agudicen. Por su parte, Forte Monge (2007) concibe al multiculturalismo como una propuesta de reconocimiento cultural y político que se apoya en algunos supuestos antropológicos y filosóficos que la convierten en un ideal de convivencia cultural 
que genera elementos deseables para la buena convivencia entre las partes, tal puede ser la lectura dada al discurso emitido por el alcalde de Nueva York el 3 de Agosto de 2010 al inaugurar una mezquita a unas cuadras de donde estuvieron las torres gemelas. Por lo tanto, las múltiples lecturas que el multiculturalismo puede tener, van de la mano de quién hace la lectura y cómo lo utiliza, pues si bien es un término lleno de buenos deseos, es una fórmula de convivialidad en desarrollo con cuerpos técnicos diversos que tiene más soporte en la práctica, y por lo tanto, no alcanza a tener el mismo peso analítico que otras corrientes presentan.

\section{La cultura en el contexto de la sociedad del conocimiento}

La revisión teórica que emprendimos muestra que la cultura como producto del género humano es relevante para generar sentido en la vida cotidiana y simbólica de los pueblos e individuos. Sin embargo, la propia teorización de esta noción nos habla de que aun cuando siempre es relevante, los significados de las acciones se modifican de acuerdo a los contextos y la cultura se ve supeditada a otras fuerzas sociales, como son la política y la economía. Por lo tanto, en un momento histórico como el actual, donde el mercado y la disminución o eliminación de reglas comerciales representa uno de los valores o incluso el valor organizativo y simbólico más importante de la sociedad, la cultura aparece como un ente simbólico ajeno a otros círculos de actividad humana, o si se prefiere de la vida social como la declaraba Levi-Strauss, para convertirse en inminente producto del mercado, susceptible de generar ganancias importantes y convertirse en un sector comercial de gran valía. La cultura de masas, así como la global, tienen por base estructural la globalización de la economía capitalista, hecha posible por las nuevas tecnologías de información/comunicación. A los ojos de Adorno y Horkheimer, de la escuela de Fráncfort, (Wiggershaus 2010) el modo de producción de la cultura de masas es el industrial, lo que da por resultado la producción de una cultura "serializada", estandarizada y marcada por la división de trabajo. Además, la transformación del acto cultural en valor económico, según estos mismos autores, cancela su poder crítico y disuelve todo rasgo de una experiencia auténtica. Lo anterior es cuestionable pues en esta sociedad dominada por el libre

cambio, donde todo tipo de expresión cultural ha sido incluida en el mercado 
y éste ha modificado los patrones culturales, vemos como, en contraparte, la cultura también es capaz de modificar el mercado. En algunos ámbitos dentro de la globalización la interacción es más intensa y por lo tanto, las posibilidades de vinculación y adaptación de los significados de los objetos culturales se transforman, pues son los usos los que transforman los significados y las formas de los productos industriales en culturales, como señala Arvidsson en el caso de las motocicletas vespa la cual se convirtió en símbolo de la juventud italiano en la década de los 70's (2001). Aquellos que se entienden como productos sociales pueden ser, y son apropiados con fines distintos a los propuestos por el mercado. Tales son también los casos de expresiones como las planteadas por sitios como Facebook, Twitter, etc., los cuales se han convertido en medios de comunicación e interacción entre grupos sociales que de otro modo no habrían tenido posibilidad de interactuar, a pesar de la confluencia de sus intereses. Es decir, al contrario de las concepciones iniciales donde se asumía que el desarrollo de la ciencia y la tecnología sería unilateral y el ciudadano común tomaría una actitud pasiva frente a sus productos, el día de hoy, la multilateralidad que permiten las nuevas tecnologías ha re significado los usos y alcances de las mismas, permitiendo así que las formas interactivas le devuelvan la agencia -si bien acotada- a los sujetos desde los contextos individuales y la amplia construcción de redes que se tienen relativamente a la mano. Esto genera expresiones más expeditas -como el movimiento en octubre de 2009 de los twitteros para que no se le aplicaran impuestos al Internet- . También es cierto que el acceso y manejo de estas tecnologías no es universal, que siguen respondiendo a los patrones hegemónicos de la posesión del capital económico, social y cultural y los medios de producción. Por otra parte, es necesario considerar que el número de horas de trabajo ha ido en aumento, hecho que implica la reducción de horas de interacción fuera del centro laboral y la disminución de interacciones sociales, lo cual implica el posible desdibujamiento de las redes sociales primarias y las interacciones simbólicas cotidianas que han sustentado tradicionalmente la interacción social en la que se construyen identidad, memoria y cultura. Sin embargo, por estos otros medios se están construyendo otras formas de interacción social y por lo tanto otras prácticas culturales. El hecho es que la cultura pasa a ser un objeto de mercado más, y uno de los más importantes a partir de lo cuantio- 
sas que resultan las transacciones comerciales hechas con códigos abstractos como son: los recursos tecnológicos, los medios de comunicación y otras industrias culturales cuyo producto comercial está grabado en el símbolo, en elementos generados a partir de códigos semióticos. El panorama presentado aquí pudiera ser alarmante, e incluso desolador, si sólo se consideran las monumentales fuerzas del mercado. Sin embargo, gracias a que la cultura tiene tantas aristas, la producción cultural continúa en todas las comunidades, aunque estas no pasen intrínsecamente por el mercado. Así tenemos expresiones culturales de constante producción e invención que aún no están marcadas por el mercado y no necesariamente son susceptibles de entrar en él. En este sentido es posible afirmar que si en virtud de las fuerzas del capital, hoy como desde hace siglos una parte de la cultura es manejada, regulada e incluso estereotipada por los grupos hegemónicos que son capaces de instalar su visión sobre el mundo, éstos no son los únicos grupos que tienen, crean y transforman la cultura, pues también están presentes los grupos sociales de base que elaboran y sostienen sus propios productos culturales de manera cotidiana. Por otra parte, está también el sector de las industrias culturales, las cuales desde las tecnologías y la interpretación de los códigos y su explotación industrial ponen en circulación los significados y resignificados de los códigos culturales, las cuales en ocasiones están más interesadas en la circulación del símbolo que en el significado mismo, con las imprevisibles consecuencias que esto genera. Además, las instituciones públicas, especialmente las establecidas por el Estado, aún tienen un papel importante en la producción cultural, a pesar de los recortes presupuestales y las reestructuraciones organizativas impuestas por el neoliberalismo, como impulsoras de aquéllas manifestaciones culturales ignoradas por los agentes del mercado. Sin embargo, en esta tónica también se generan expresiones culturales que van en contrasentido, que cuestionan los cánones sociales y culturales de su tiempo y son las que eventualmente son más susceptibles de traer modificaciones, o al menos cuestionamiento, a las prácticas culturales vigentes en las comunidades y generar nuevas prácticas capaces de modificar los sentidos de la vida cotidiana, como en los casos que han desarrollado los activistas verdes como Greenpeace o PETA, grupos sociales-culturales que aparecen y toman fuerza donde los tradicionales como los sindicatos o congregaciones religiosas tienden a debilitarse o transformar 
sus labores. Además, en esta misma tónica están los grupos culturales que trabajan en la reinterpretación de los códigos culturales ya existentes, como serían los grupos de Son Jarocho (Cardona 2006), los grupos de Science for All desarrollados en la India desde los años setenta (Kannan 1990), o los nuevos esquemas de economía solidaria (Vietmeier 2005), por mencionar algunos.

En resumen, el día de hoy estos serían grupos que no solo generan cultura, sino además lo hacen de modo consciente teniendo en cuenta los valores simbólicos, sociales, políticos y mercantiles que ésta representa en las condiciones actuales. Algunos lo hacen de modo más consciente que otros, sin embargo, sería recomendable que más comunidades identificadas como no hegemónicas o dominadas tuvieran claridad en el peso de sus acciones para generar espacios de interacción más equitativos que permitieran una convivencia multicultural, o incluso intercultural, con mayores beneficios para todos los seres humanos en estos tiempos en que la cultura Es un activo muy provechoso en el mercado global y lo cual, ha implicado la disminución de sus cualidades simbólicas e identitarias particulares.

\section{Referencias}

Ardvisson, A. 2001, "From Counterculture to Consumer Culture. Vespa and the Italian youth marke, 1958-78", Journal of Consumer Culture, Vol. 1, No 1 47-71.

Bassand, M., 1981, Lidentité régionale, Editions Georgi, Saint Saphorine

Bourdieu, P., 2002, La distinción: criterios y bases sociales del gusto, Taurus, México.

—_, 1980, Le sens practique, Les Éditions de Minuit, París.

—_, 1990, "Algunas propiedades de los campos", en Sociología y cultura, Grijalbo, Conaculta, México.

Brummett, B., 1994, Rhetoric in Popular Culture, St. Martin's Press, Nueva York.

Cardona, I., 2006, "Los actores culturales entre la tentación comunitaria y el mercado global: el resurgimiento del Son Jarocho", en Arizpe, L. (Coord.), Los retos culturales de México frente a la globalización, Miguel Ángel Porrúa, México.

De Varine, H., 1976, La cultura des autres, Editions du Seuil, París.

Di Cristoforo Longo, G., 1993, Identitá e cultura, Edizioni Studium, Roma.

Forte, J. M., 2007, "Multiculturalismo, Identidad y Reconocimiento". Themata, Revista de Filosofía. No 39, pp. 613-618.

Geertz, C., 1992, La interpretación de las culturas, Editorial Gedisa, Barcelona.

Giménez, G., 2005, Teoría y Análisis de la cultura, Vol. 1, Intersecciones, México. , 1983, Poder, Estado y discurso UNAM, México.

Gramsci, A., 1975, Quaderni del carcere, Vol. III, Giulio Einaudi Editore. 
Greimas, A.J. y Courtès, J., 1979, Sémiotique, Hachette, Université Paris.

Imbert, M., 1979, en Poujol, G. y R. Labourie, Les cultures populaires, Privat, París, 1979.

Charpentraux, J. y Kaës, R., 1962, La culture populaire en France, Éditions Ouvrières, París.

Jodelet, D., (ed.), 1989, Les representations socials, PUF, Paris.

Kannan, K. P., 1990, "Secularism and People's Science Movement in India”, En Economic and Political Weekly, Mumbai, vol. 25, pp. 311-313.

Organización de las Naciones Unidas, UNESCO, 1982, Declaración de México sobre las políticas culturales. Conferencia mundial sobre las políticas culturales, 26 de julio-6 de agosto 1982, en

http://portal.unesco.org/culture/es/files/12762/11295424031mexico_sp.pdf/ mexico_sp.pdf

Thompson, J., 1990, Ideología y cultura moderna, Universidad Autónoma MetropolitanaXochimilco, México.

Touraine, A., 1997, ¿̇odremos vivir juntos?, Iguales y diferentes, PPC Editorial, Madrid.

Tylor, E., 1871, Primitive Culture: Researches Into the Development of Mythology, Philosophy, Religion, Language, Art and Custo. J. Murray, Londres.

Velasco, J, C., 2000, "El multiculturalismo: ¿Una nueva ideología?, Alcance y límites de la lucha por las identidades culturales", en Alcina, J. y Calés, M., (ed.), 2000, Hacia una ideología para el siglo XXI, Akal, Madrid.

Vietmeier, A., 2005, "Economía solidaria en México: Tesis y retos", en

http://vinculando.org/economia_solidaria/vietmeier_ecosol.html

Warnier, J. P., 2004, La mondialisation de la cultura, Collection Repères, La découverte, París.

Wiggershaus, R., 2010, La escuela de Fráncfort, Fondo de Cultura Económica, México.

Recibido el 2 de Febrero de 2011

Aceptado el 15 de Febrero de 2011 